OPEN ACCESS

Edited by:

Su Shiung Lam,

University of Malaysia

Terengganu, Malaysia

Reviewed by:

Fehmi Akgun,

TUBITAK Marmara Research Centre

Energy Institute, Turkey

Peter Nai Yuh Yek,

University College of Technology

Sarawak, Malaysia

*Correspondence:

Despina Vamvuka

vamvuka@mred.tuc.gr

Specialty section

This article was submitted to

Bioenergy and Biofuels,

a section of the journal

Frontiers in Energy Research

Received: 27 August 2019

Accepted: 04 June 2020

Published: 08 July 2020

Citation:

Vamvuka D, Loukeris D, Stamou E

Vlasiadis A, Sfakiotakis $S$ and

Bandelis G (2020) Development and

Performance of a Multi-Fuel

Residential Boiler Burning Agricultural

Residues. Front. Energy Res. 8:136

doi: 10.3389/fenrg.2020.00136

\section{Development and Performance of a Multi-Fuel Residential Boiler Burning Agricultural Residues}

\author{
Despina Vamvuka ${ }^{1 *}$, Dimitrios Loukeris ${ }^{1}$, Evaggelos Stamou ${ }^{1}$, Aristotelis Vlasiadis ${ }^{1}$, \\ Stelios Sfakiotakis ${ }^{1}$ and Grigorios Bandelis ${ }^{2}$
}

${ }^{1}$ School of Mineral Resources Engineering, Technical University of Crete, Chania, Greece, ${ }^{2}$ Energy Mechanical of Crete S.A., Chania, Greece

The combustion behavior of selected agricultural residues (olive and peach kernels, almond and walnut shells) and their blends was investigated in a prototype low-investment combustion unit of nominal capacity $65 \mathrm{~kW}$ th. Blending ratio for olive kernel was 50 or $70 \%$, while for the rest of the residues 30 or $50 \%$. Flue gas temperatures, inlet and outlet water temperatures of the boiler and gaseous emissions were measured at specific feed and air flow rates and combustion and boiler efficiencies were determined. $\mathrm{CO}$ and $\mathrm{NO}_{\mathrm{x}}$ emissions from all fuels during the whole operation of the unit were below legislation limits, while $\mathrm{SO}_{2}$ emissions were negligible. Combustion efficiencies were satisfactory, ranging between 84 and $86 \%$. Peach kernels burned with the highest efficiency. By blending olive kernels with peach kernels, almond or walnut shells at percentages up to $50 \%$, the overall efficiency of the system in terms of emissions and degree of combustion was improved, achieving the best performance with olive kernels/peach kernels 50:50 blend. Co-combustion of unpelletized materials could be predicted to a great extent from the combustion of component fuels, offering apart from environmental and economic benefits.

Keywords: agricultural residues, blends, combustion, stoker burner, emissions, efficiency

\section{INTRODUCTION}

Population growth, depletion and rising cost of fossil fuels and climate crisis across the world require rapid development of renewable energy technologies, with minimum environmental impact. Biomass fuels have a remarkable potential in meeting these needs, due to their abundance, low cost and reduction of greenhouse emissions. Up to 33-50\% of the world's current consumption could be met by biomass by 2050 (McKendry, 2002).

EU has set the target to increase the share of renewable energy in its total energy consumption to $27 \%$ by the year 2030 (EU, 2014). Woody fuels have been predominantly used for both large and small scale systems, for heat or power production. However, the increasing competition for such fuels in the heating sector, sawmills and paper industries, as well as the increase in wood pellet production, have raised the price of wood and resulted in raw material shortage (Uslo et al., 2010). Thus, to fulfill the goal of growth of biomass utilization, a wider assortment of raw materials will be required (Carvalho et al., 2013; Cardozo et al., 2014; Zeng et al., 2018), creating a further need for fuel processing and emission control technologies. 
For South European countries, where residential heating with biomass fuels as a cheaper alternative is growing, agricultural and agro-industrial residues are the feedstock of choice. They are readily available in large quantities and they have a high energy potential, reducing by combustion the volume of wastes and increasing economic returns to rural communities. In Greece, about 4 million tons/year are available and equivalent to approximately $50 \%$ of the gross energy consumption (Vamvuka and Tsoutsos, 2002; Vamvuka, 2009).

The common types of residential combustion devices are wood stoves, wood log boilers, wood pellet stoves and wood chip appliances. Apart from wood stoves and conventional boilers with endless screws, mixed combustion boilers are being used, featuring automation add-ons, storing solutions and a variety of feeding mechanisms (Vamvuka, 2009; Sutar et al., 2015; Ahn and Jang, 2018). Past studies have investigated flue gas emissions, efficiency and ash related problems, during combustion of agricultural residues. Large scale units or small pellet appliances for domestic or residential central heating, some using top feeding, rotary or moving grates (Vamvuka, 2009; Carvalho et al., 2013; Rabacal et al., 2013; Garcia-Maraver et al., 2014; Pizzi et al., 2018; Zeng et al., 2018; Nizetic et al., 2019), have been extensively investigated. However, there is still not enough information on the performance of unpelletized raw materials in terms of efficiency and pollutant emissions according to threshold values, as a function of different small system designs and operating conditions. Wood chips have been principally used (Kortelainen et al., 2015; Caposciutti and Antonelli, 2018), whereas the development of boilers in Mediterranean countries is slow.

Small scale biomass systems have been proved to significantly contribute to local air quality through emissions of pollutants, such as $\mathrm{CO}, \mathrm{SO}_{2}, \mathrm{NO}_{\mathrm{x}}$, polyaromatic hydrocarbons and particulate matter, which can seriously affect human health and climate. These emissions depend on fuel properties, technology implemented and process conditions and their monitoring and controlling is very important in order to meet environmental limits and cost-effectiveness of market demands. CO emissions have been found to vary between 600 and $680 \mathrm{ppm}_{\mathrm{V}}$ for peach pits (Rabacal et al., 2013), 50-400 $\mathrm{ppm}_{\mathrm{V}}$ for Brazilian nut shells and 100-400 $\mathrm{ppm}_{\mathrm{v}}$ for sunflower husks (Cardozo et al., 2014). $\mathrm{NO}_{\mathrm{x}}$ emissions have been shown to range between $300-600 \mathrm{mg} / \mathrm{m}^{3}$ for peach pits (Rabacal et al., 2013), $180-270 \mathrm{mg} / \mathrm{m}^{3}$ for Brazilian nut shells and $50-720 \mathrm{mg} / \mathrm{m}^{3}$ for sunflower husks (Cardozo et al., 2014). For the latter, $\mathrm{SO}_{2}$ emissions varied between 78 and 150 $\mathrm{mg} / \mathrm{m}^{3}$. Boiler efficiency has been reported (Rabacal et al., 2013; Fournel et al., 2015) to range between 63 and 83\%, depending on fuel type.

As agricultural residues are available only in limited periods throughout a year, mixtures of them would increase supply options for operating plants. However, when mixtures are used as feedstock the compatibility of the fuels with respect to combustion performance has to be properly evaluated, for the effective design and operation of the combustion units. The variable composition of these materials implies a thorough knowledge of their behavior in thermal systems, in order to avoid fuel combinations with unwanted properties. To authors' knowledge, blends of such wastes found at low or no cost have not been investigated in residential appliances. Only pellets of woody fuels or energy crops have been used to determine particulate emissions and slag formation (Carroll and Finnan, 2015; Sippula et al., 2017; Zeng et al., 2018).

Based on the above, the aim of present study was to compare the combustion behavior of selected unpelletized agricultural residue materials, which are abundant in South European countries and mixtures of them, in order to investigate any additivity or synergy effects among component fuels and gain knowledge about the use of such blends in small scale boilers. The objective was to evaluate the performance of a prototype lowinvestment combustion unit, allowing pre-drying of fuels and combustion air by exhaust fumes, for the production of thermal energy in buildings, farms, small enterprises and green houses, in terms of important parameters, such as combustion and boiler efficiency, flue gas temperature and environmental emissions.

\section{EXPERIMENTAL SECTION}

\section{Fuels and Characterization}

The agricultural residues of this study were selected on the basis of their abundance and availability in Greece and Mediterranean countries, in general. These were olive kernels $(\mathrm{OK})$ provided by AVEA Chania Oil Cooperatives (S. Greece), peach kernels (PK) provided by the Union of Agricultural Cooperatives of Giannitsa (N. Greece), almond shells (AS) provided by a private company (Agrinio, C. Greece) and walnut shells (WS) provided by Hohlios company (N. Greece).

After air drying, homogenization and riffling the materials were ground to a particle size $<6 \mathrm{~mm}$, using a jaw crusher and vibrative dry sieving. Representative samples were ground to a particle size of $-425 \mu \mathrm{m}$ by a cutting mill and characterized by proximate analysis, ultimate analysis and calorific value, according to the European standards CEN/TC335. Volatiles content was measured by thermogravimetric analysis, using a TGA-6/DTG system, in the range of $25-900^{\circ} \mathrm{C}$, under a flow of nitrogen of $45 \mathrm{ml} / \mathrm{min}$ and at a linear heating rate of $10^{\circ} \mathrm{C} / \mathrm{min}$. Chemical analysis of ashes was performed by an Xray fluorescence spectrophotometer (XRF), type Bruker AXS S2 Ranger (anode Pd, 50 Watt, 50 kV, $2 \mathrm{~mA}$ ). Deposition tendency of ashes was predicted through the use of empirical indices. These indices, despite their shortcomings due to the complex conditions, which arise in boilers and their associated heat transfer equipment, are widely used and probably remain the most secure basis for decision making, if used in conjunction with pilot plant testing.

The base-to-acid ratio (Equation 1) is a useful index, since typically a high percentage of basic oxides lowers the melting temperature, while acidic oxides increase it. This takes the form (Vamvuka et al., 2017):

$$
R_{b / a}=\frac{\%\left(\mathrm{Fe}_{2} \mathrm{O}_{3}+\mathrm{CaO}+\mathrm{MgO}+\mathrm{K}_{2} \mathrm{O}+\mathrm{Na}_{2} \mathrm{O}\right)}{\%\left(\mathrm{SiO}_{2}+\mathrm{TiO}_{2}+\mathrm{Al}_{2} \mathrm{O}_{3}\right)}
$$

where the label for each compound makes reference to its weight concentration in the ash. When $\mathrm{R}_{\mathrm{b} / \mathrm{a}}<0.5$ deposition tendency 


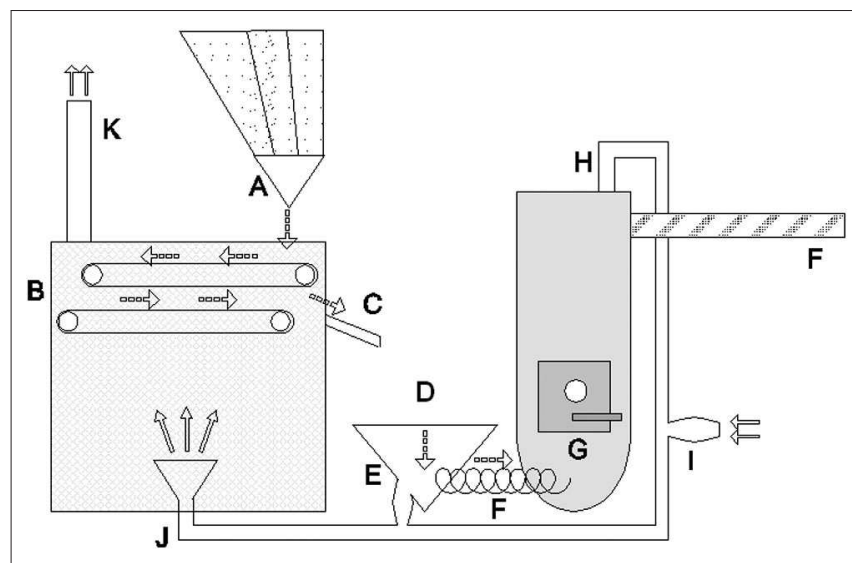

FIGURE 1 | Schematic diagram of multi-fuel boiler (solid arrows show air flow direction, while dotted arrows show biomass flow direction).

is low, when $0.5<\mathrm{R}_{\mathrm{b} / \mathrm{a}}<1$ deposition tendency is medium and when $R_{b / a}>1$ deposition tendency is high. For $R_{b / a}$ values $>2$, this index cannot be used safely without additional information.

The influence of the alkalis in the slagging/fouling tendency of the biomass ashes is critical, due to their tendency to lower the ash melting temperature. One simple index, the alkali index (Equation 2), expresses the quantity of alkali oxides in the fuel per unit of fuel energy in GJ (Vamvuka et al., 2017):

$$
\mathrm{AI}=\frac{\mathrm{kg}\left(\mathrm{K}_{2} \mathrm{O}+\mathrm{Na}_{2} \mathrm{O}\right)}{\mathrm{GJ}}
$$

When AI values are in the range $0.17-0.34 \mathrm{~kg} / \mathrm{GJ}$ fouling or slagging is probable, while when these values are $>0.34$ fouling or slagging is virtually certain to occur.

For combustion tests, mixtures of above materials with blending ratios up to $50 \%$ by weight were prepared with the most abundant agricultural waste in Greece, olive kernels.

\section{Description of Prototype Combustion System}

The combustion unit is illustrated schematically in Figure 1. The main parts are two silos, a desiccator, a continuous feedstock supply system and a cross flow boiler. The nominal capacity is $65 \mathrm{~kW}_{\text {th }}$.

The fuel is stored in a main silo (A), the side surfaces of which are perforated, to dry the fuel physically. According to the availability of the biomass and the special energy needs, a regulating valve is opened and the system is fed with the appropriate fuel. The biomass is then transferred from the silo to the desiccator through an inclined rack with tracks, with a speed that is controlled according to the needs of the boiler. The hot air is provided by the exhaust fumes, through a feedback system $(\mathrm{H}, \mathrm{J})$. The dryer hosts two inner conveyor belts (B) consisted of perforated slow-turning rollers with steel netting, enabling hot air to travel thought it in a bottom-up flow direction. The dryer (B) has several compartments, so as to allow the air to travel and eventually lose a part of its temperature, thus creating a temperature difference. The special steel netting has high endurance and it can handle the extreme temperature variances quite efficiently. The speed of the rollers is closely connected to the humidity of the biomass and can vary according to the needs of the automatic control. The dry biomass is then transferred (C) to a temporary silo (D) and mixed with warm air coming from the feedback system (E), before it is led to the burner and the combustion area of the boiler. Using a horizontal warm screw, $1 \& 1 / 2$ inch in diameter, the processed biomass is fed into the burner $(\mathrm{G})$. The feed rate is controlled via two electronic dimmers. The first dimmer corresponds to the time that the feeding system is operating, while the second dimmer corresponds to the delay time (screw is off). In this way, the feedstock supply follows a semi-batch process. Primary combustion air is introduced through a pipe in the front of the furnace and it is controlled with a blower. The ratio of primary to secondary air is adjusted by use of a regulator installed in the exhaust flue $(\mathrm{K})$, with a mechanic regulator that permits variations of the chimney draft. The boiler $(\mathrm{G})$ is hydraulic and it primarily produces hot water in a closed-loop circulating system (F). This system has security arrangements, to keep the water pressure constant and transports hot water to high efficiency fan coils for space heating. Pt temperature sensors are used for measurement of the water temperatures of the forward and return flow, as well as of the flow inside the boiler. A calorific value meter is measuring the flow of water and the useful energy picked up by the water. The exhaust fumes of the boiler are driven through a heat exchanger before they go to the chimney. The heat exchanger (I) uses the exhaust fumes to warm-up air, which is then used for the drying of the wet biomass.

The novelty of this prototype unit is the design of the desiccator fed with exhaust fumes, handling extreme temperature variances and running according to boiler needs, the heat exchanger also fed with exhaust fumes, as well as the temperature sensors and calorific value meter enclosed. Because all main parts of the unit are conventional, the manufacturing cost of such installation is kept low. The analog sensors and parts already installed will be replaced with digital sensors and mechanical parts with digital inputs and outputs, according to the results of the unit response experiments. A limitation of the system is the inability to adjust an optimal excess air ratio, so that there is a need for robust control of combustion air supplied. Determination of optimal parameters of a custom automatic control system should be adopted, to allow the unit to run autonomously.

\section{Experimental Procedure and Data Measurements}

The experiments were structured in such way, so that an analytical profile of each material could be built and also the behavior of fuel type during the different stages of the process could be investigated. Two series of experiments were conducted, in order to study the behavior and response of each residue to the processing chain of the unit. During the first series of tests, a calibration of the feeding rate vs. the dimmer switches was carried out for each biofuel. The feed rate was determined 
by the on-off delay interval sequences, of the first and second dimmer, respectively. The flow rate of flue gases, for each feedstock supply, was determined by measuring the speed of the fan at the gas exit installed in position (K), by an anemometer. Consequently, each biofuel was tested in the combustion unit in order to optimize the thermal efficiency by tuning its special parameters, taking into account the quality of the emissions. Important independent variables were the feedstock supply rate, the speed of the fan controlling the air flow of the boiler and the boiler inner temperature. Present study reports the results for one set of these parameters, aiming to compare the combustion performance between the agricultural residues tested, as well as of their blends, under constant operating conditions. The parametric study for the optimization of the process will be presented in a following report.

To start up the boiler, the fuel was ignited and the solid feeder and air lines were turned on and set to the desired values (on/off $10 / 30 \mathrm{~s} / \mathrm{s}$ ). The furnace was allowed to run for $30 \mathrm{~min}$ before the first readings were taken. The hot water circulating system was adjusted to operate, once the temperature was $\geq 55^{\circ} \mathrm{C}$. When water temperature exceeded $70^{\circ} \mathrm{C}$, the supply of feedstock was temporarily stopped.

Flue gas composition was continuously monitored during the tests, by a multi-component gas analyzer, model Madur GA-40 plus of Maihak, equipped with double-in-line filter and dryer. The sampling was achieved using a heating line with a probe, according to the ELOT 896 Greek standards. The analyzer uses electrochemical sensors for the measurement of gas concentrations. The $\mathrm{CO}_{2}, \mathrm{CO}, \mathrm{O}_{2}, \mathrm{SO}_{2}, \mathrm{NO}_{\mathrm{x}}$ contents in the exhaust gas stream, the soot index, the heat losses of the fumes, the flue gas temperature and the excess air coefficient $(\lambda)$ were continuously recorded by the analyzer. The analog output of the analyzer was transmitted to a computer, where the signals were processed and the mean values computed over a sampling period of $0.5 \mathrm{~min}$.

After taking measurements at steady operating conditions and allowing the furnace to run for about $3 \mathrm{~h}$, the fuel feeder and air line were turned off, the view port was opened and the exhaust fan was set on high to cool the unit. Bottom ash was drained, weighed and analyzed for combustion losses due to unburned carbon. The experiments were replicated twice to determine their reproducibility, which was found to be good.

The thermal efficiency of the system was defined as the proportion of the useful energy picked up by the water of the boiler, to the input energy produced by the fuel:

$$
\eta_{t}=\frac{Q_{o u t}}{Q_{\text {in }}}=\frac{q_{w} c_{p w} \Delta T_{w} \Delta t}{m_{f} Q_{f}}(\%)
$$

where, $\mathrm{q}_{\mathrm{w}}$ : mass flow of water $(\mathrm{kg} / \mathrm{h}), \mathrm{c}_{\mathrm{pw}}$ : thermal capacity of water $(\mathrm{MJ} / \mathrm{kgK}), \Delta \mathrm{T}_{\mathrm{w}}$ : temperature difference of the forward and return flow of water $\left({ }^{\circ} \mathrm{K}\right), \Delta \mathrm{t}$ : total combustion time at water temperature $70^{\circ} \mathrm{C}, \mathrm{m}_{\mathrm{f}}$ : mass of fuel $/$ mixture burned $(\mathrm{kg}), \mathrm{Q}_{\mathrm{f}}$ : calorific value of fuel $/$ mixture $(\mathrm{MJ} / \mathrm{kg})$.

Combustion efficiency was defined as follows:

$$
\eta_{c}=100-S L-I L-L_{a}(\%)
$$

where,

$$
\begin{array}{r}
S L=\left(T_{f}-T_{a m b}\right)\left(\frac{A}{\left[\mathrm{CO}_{2}\right]}+B\right) \\
I L=\frac{a[\mathrm{CO}]}{[\mathrm{CO}]+\left[\mathrm{CO}_{2}\right]} \\
L_{a}=100-\frac{m_{o}-m_{a}}{m_{o}}
\end{array}
$$

where: $\mathrm{T}_{\mathrm{f}}$ : temperature of flue gases $\left({ }^{\circ} \mathrm{C}\right), \mathrm{T}_{\mathrm{amb}}$ : temperature of ambient air $\left({ }^{\circ} \mathrm{C}\right),[\mathrm{CO}]$ and $\left[\mathrm{CO}_{2}\right]$ : concentrations of $\mathrm{CO}$ and $\mathrm{CO}_{2}$ in flue gases (\%), $\mathrm{A}, \mathrm{B}$, a: combustion parameters characteristic for each type of fuel (given by the analyzer), $\mathrm{m}_{\mathrm{o}}$ : total mass of organic matter of fuel burned $(\mathrm{kg}), \mathrm{m}_{\mathrm{a}}$ : mass of organic matter in ash $(\mathrm{kg})$.

For each experimental test it was examined whether the available heat of the flue gas was enough to preheat the inlet air for the combustion of the fuel to $70^{\circ} \mathrm{C}$ and also to dry the biomass in the system dessicator:

$$
Q_{f l} \geq Q_{a m b}+Q_{d}
$$

or

$$
m_{f l} c_{p f l} \Delta T_{f} \geq m_{a m b} c_{p a m b} \Delta T_{a m b}+Q_{d}
$$

where: $\mathrm{m}_{\mathrm{fl}}, \mathrm{m}_{\mathrm{amb}}$ : mass of flue gases and air per $\mathrm{kg}$ of biomass burned $(\mathrm{kg}), \mathrm{c}_{\mathrm{pfl}}, \mathrm{c}_{\mathrm{pamb}}$ : specific heat of flue gas and air $\left(\mathrm{kJ} / \mathrm{kg}^{\circ} \mathrm{K}\right)$, $\Delta \mathrm{T}_{\mathrm{f}}, \Delta \mathrm{T}_{\mathrm{amb}}$ : temperature difference of flue gases at the exit and inlet of the chimney and of preheated air and ambient air, respectively $\left({ }^{\circ} \mathrm{K}\right), \mathrm{Q}_{\mathrm{d}}$ : heat of biomass drying (Moyers and Baldwin, 1997). According to the results which follow, the above inequality always held.

\section{RESULTS AND DISCUSSION}

\section{Raw Fuel Analyses}

Table 1 indicates the proximate and ultimate analyses of the agricultural residues studied. As can be observed, all samples were rich in volatile matter and had low ash contents. Almond shells presented the highest percentage of volatiles, whereas walnut shells the lowest percentage of ash. The concentration of oxygen was significant for all samples and the calorific value, ranging between 17.5 and $20.4 \mathrm{MJ} / \mathrm{kg}$, was comparable to the upper limit of low rank coals. The sulfur content of all residues was practically null, revealing that $\mathrm{SO}_{2}$ emissions are not of concern for these biofuels. On the other hand, the nitrogen content of almond shells was considerable, which might be a problem during thermal processing, in terms of $\mathrm{NO}_{\mathrm{x}}$ emissions.

The chemical analysis of ashes, expressed in the usual way for fuels as oxides, is compared in Table 2, together with the slagging/fouling indices and deposition tendency. The common feature of these ash materials is that they were rich in $\mathrm{Ca}$ and $\mathrm{K}$ and to a lesser extent in $\mathrm{P}$ and $\mathrm{Mg}$. The base-to-acid ratio was far $>2$, due to the low silica and alumina content of these ashes, so that no definite guidelines for slagging bahavior can be drawn. The alkali induced slagging/fouling potential can be 
TABLE 1 | Proximate and ultimate analyses and calorific value of the samples (\% dry weight).

\begin{tabular}{|c|c|c|c|c|c|c|c|c|c|}
\hline Sample & Volatile matter & $\begin{array}{l}\text { Fixed } \\
\text { carbon }\end{array}$ & Ash & C & $\mathbf{H}$ & $\mathbf{N}$ & 0 & $\mathbf{S}$ & $\begin{array}{c}\text { GCV }^{a} \\
\text { (MJ/kg) }\end{array}$ \\
\hline Olive kernels (OK) & 78.2 & 14.5 & 7.3 & 49.5 & 6.3 & 0.9 & 36.0 & $<0.05$ & 20.4 \\
\hline Peach kernels (PK) & 76.2 & 19.4 & 4.4 & 48.0 & 5.9 & - & 41.7 & $<0.05$ & 18.9 \\
\hline Almond shells (AS) & 81.4 & 13.1 & 5.5 & 46.5 & 5.7 & 2.2 & 40.1 & $<0.05$ & 17.5 \\
\hline Walnut shells (WS) & 72.1 & 26.5 & 1.4 & 48.5 & 6.3 & 0.8 & 43.0 & $<0.05$ & 19.5 \\
\hline
\end{tabular}

${ }^{a}$ Gross calorific value.

TABLE 2 | Chemical analysis of raw material ashes and slagging/fouling tendency.

\begin{tabular}{|c|c|c|c|c|c|c|c|c|c|c|c|c|}
\hline \multirow[t]{2}{*}{ Sample } & \multicolumn{9}{|c|}{ Ash composition (\%) } & \multirow{2}{*}{$\begin{array}{c}\text { Base-to-acid } \\
\text { ratio } \mathbf{R}_{\mathrm{b} / \mathrm{a}}\end{array}$} & \multirow{2}{*}{$\begin{array}{c}\text { Alkali } \\
\text { index Al }\end{array}$} & \multirow{2}{*}{$\begin{array}{l}\text { Slagging/fouling } \\
\text { tendency }\end{array}$} \\
\hline & $\mathrm{SiO}_{2}$ & $\mathrm{Al}_{2} \mathrm{O}_{3}$ & $\mathrm{Fe}_{2} \mathrm{O}_{3}$ & $\mathrm{MgO}$ & $\mathrm{CaO}$ & $\mathrm{Na}_{2} \mathrm{O}$ & $\mathrm{K}_{2} \mathrm{O}$ & $\mathrm{P}_{2} \mathrm{O}_{5}$ & $\mathrm{SO}_{3}$ & & & \\
\hline OK & 4.5 & 1.4 & 1.9 & 4.9 & 26.7 & 2.7 & 28.9 & 6.6 & 5.9 & 11.0 & 1.17 & High \\
\hline PK & 2.6 & 2.6 & 4.7 & 3.7 & 27.6 & 0.4 & 4.6 & 1.8 & 3.7 & 7.8 & 0.15 & Low \\
\hline AS & 6.2 & 1.4 & 1.5 & 4.5 & 14.7 & 0.8 & 27.2 & 3.8 & 1.7 & 6.4 & 0.56 & High \\
\hline WS & 2.2 & 0.6 & 1.4 & 6.2 & 49.6 & 0.6 & 16.3 & 7.4 & 2.6 & 26.4 & 0.12 & Low \\
\hline OK/PK 70:30 & 3.9 & 1.8 & 2.7 & 4.5 & 27.0 & 2.1 & 21.7 & 5.2 & 5.2 & 10.2 & 0.72 & High \\
\hline OK/PK 50:50 & 3.6 & 2.0 & 3.3 & 4.3 & 27.1 & 1.5 & 16.5 & 4.2 & 4.8 & 9.4 & 0.49 & High \\
\hline OK/AS 70:30 & 5.0 & 1.4 & 1.8 & 4.8 & 23.1 & 2.0 & 28.2 & 5.8 & 4.6 & 9.3 & 0.96 & High \\
\hline OK/AS 50:50 & 5.3 & 1.4 & 1.7 & 4.7 & 20.7 & 1.6 & 27.8 & 5.2 & 3.8 & 8.4 & 0.95 & High \\
\hline OKWS 70:30 & 3.7 & 1.1 & 1.7 & 5.1 & 33.0 & 1.9 & 24.8 & 6.7 & 5.1 & 13.8 & 0.74 & High \\
\hline OKWS 50:50 & 3.2 & 1.0 & 1.6 & 5.4 & 37.7 & 1.6 & 22.1 & 6.9 & 4.4 & 21.4 & 0.52 & High \\
\hline
\end{tabular}

predicted more accurately by the alkali index. Thus, according to the AI values, for olive kernels and almond shells the fouling propensity is certain to occur, due to the high amounts of alkali with respect to unit of fuel energy they contain (for almond shells the propensity is much lower), while for peach kernels and walnut shells no fouling is expected in boilers. When olive kernels were mixed with the other residues at blending ratios up to $50 \%$, Table 2 shows that the AI values were significantly lowered. It must be mentioned however, that for small systems, such as the one used in this work, operating below $1,000^{\circ} \mathrm{C}$ and for a relatively short period of time, slagging or fouling phenomena due to ashes were not observed.

\section{Combustion Performance of Agricultural Residues Biofuels \\ Boiler Water Temperature}

The variation of water outlet temperature of the boiler, during full operation of the combustion unit, is illustrated in Figure 2. It is clear that peach kernels and walnut shells started burning earlier than the other two residues, offering their thermal energy to water about 6 min earlier than olive kernels for rising the temperature from 25 to $70^{\circ} \mathrm{C}$. The behavior of walnut shells, however, was quite different. Water temperature during the start up phase rose up to $78^{\circ} \mathrm{C}$ (second dimmer at off), so that for three full cycles (on/off) combustion time was extended by about $20 \mathrm{~min}$, as compared to olive kernels. For walnut and almond shells, three cycles under the conditions studied lasted about $1 \mathrm{~h}$.

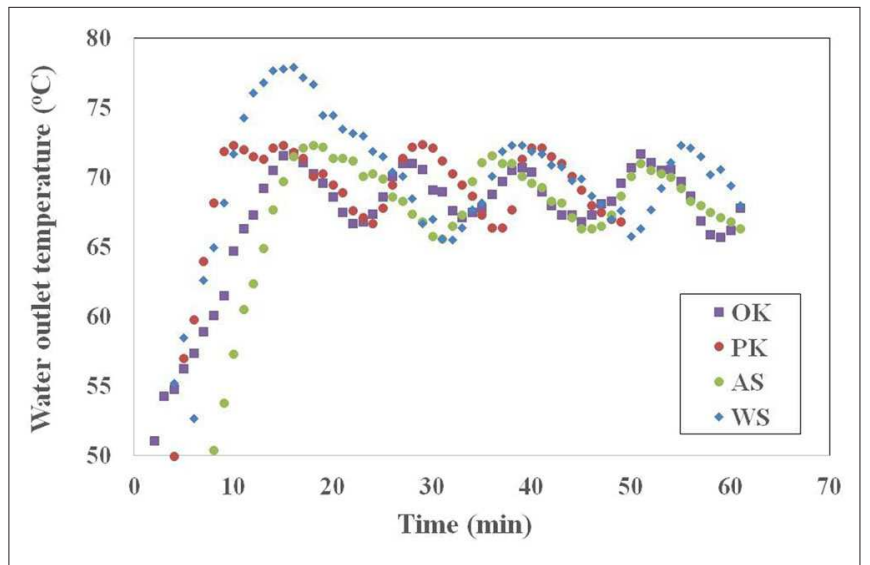

FIGURE 2 | Evolution of boiler water outlet temperature for raw fuels during full operation of the unit.

\section{Flue Gas Temperature and Emissions}

Flue gas temperature (Table 3) presents a dependence on fuel. Thus, it was higher for almond shells, $267^{\circ} \mathrm{C}$, for full boiler operation (at steady state), while lower for peach kernels, $245^{\circ} \mathrm{C}$, implying greater and lower heat losses from the furnace, respectively. All flue gas temperature values were high enough to pre-dry the raw materials (Equation 9).

$\mathrm{CO}$ concentration in flue gases at steady state operation of the furnace (dimmer at on), for the four residues under study, is 
TABLE 3 | Combustion characteristics of the fuels (average values) at steady state.

\begin{tabular}{|c|c|c|c|c|c|c|c|c|c|c|c|c|}
\hline Sample & $\begin{array}{l}\text { Fuel } \\
\text { rate } \\
(\mathrm{kg} / \mathrm{h})\end{array}$ & $\begin{array}{l}\text { Stoich. air } \\
\text { rate per kg } \\
\text { fuel }\left(\mathrm{m}^{3} / \mathrm{h}\right)\end{array}$ & $\begin{array}{c}\text { Excess } \\
\text { air ratio } \\
\lambda\end{array}$ & $\begin{array}{c}\text { CO } \\
\left(p p m_{V}\right)\end{array}$ & $\begin{array}{c}\mathrm{SO}_{2} \\
\left(\mathrm{ppm}_{\mathrm{V}}\right)\end{array}$ & $\begin{array}{c}\mathrm{NO}_{\mathrm{x}} \\
\left(\mathrm{ppm}_{\mathrm{V}}\right)\end{array}$ & $\begin{array}{c}\mathrm{T}_{\mathrm{f}} \\
\left({ }^{\circ} \mathrm{C}\right)\end{array}$ & $\begin{array}{l}\text { SL } \\
(\%)\end{array}$ & $\begin{array}{c}\text { IL } \\
(\%)\end{array}$ & $\begin{array}{c}L_{a} \\
(\%)\end{array}$ & $\begin{array}{c}\eta_{c} \\
(\%)\end{array}$ & $\begin{array}{c}\eta_{\mathrm{t}} \\
(\%)\end{array}$ \\
\hline OK & 13.5 & 5.6 & 1.9 & 1224.7 & 3.0 & 136.1 & 241.0 & 14.1 & 1.0 & 0.4 & 84.5 & 86.3 \\
\hline PK & 18.0 & 4.7 & 1.5 & 1014.5 & 9.2 & 81.9 & 245.2 & 13.2 & 0.9 & 0.1 & 85.8 & 93.4 \\
\hline AS & 15.3 & 4.5 & 1.8 & 1194.4 & 10.6 & 81.7 & 267.6 & 14.6 & 1.0 & 0.2 & 84.2 & 90.5 \\
\hline WS & 13.8 & 5.1 & 1.7 & 1145.0 & 12.4 & 88.0 & 244.8 & 13.4 & 1.0 & 0.1 & 85.5 & 87.4 \\
\hline
\end{tabular}

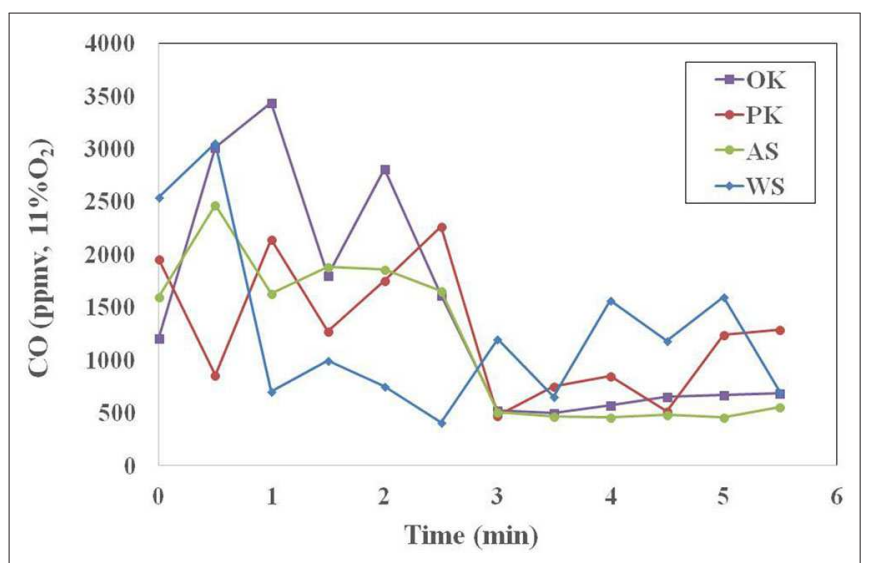

FIGURE 3 | CO concentration in flue gases for raw fuels at steady state.

compared in Figure 3. The increased CO levels of olive kernels biofuel were most probably attributed to its great amount of volatiles, which boost hydrocarbons concentration in the reactor, inhibiting further oxidation of $\mathrm{CO}$ to $\mathrm{CO}_{2}$, as well as to a lesser extent the higher ash content of this fuel, which weakened oxygen penetration to the char particles. Nevertheless, all CO values were below legislation limits for small scale systems (ELOT, 2011).

The average pollutant concentrations ( \pm standard error) at steady state and during the whole operation of the unit are represented and compared in Figures 4A,B, respectively. $\mathrm{SO}_{2}$ emissions from all biofuels, being extremely low $\left(0-13 \mathrm{ppm}_{\mathrm{V}}\right)$, were omitted from the graphs. Figure $4 \mathrm{~A}$ shows that the highest $\mathrm{CO}$ emissions were released from olive kernels combustion, while the lowest from peach kernels combustion. However, even though during full boiler operation (including intervals with no fuel feeding, i.e., second dimmer at off) $\mathrm{CO}$ values were higher (Figure 4B), they did not exceed allowable limits (ELOT, 2011). Furthermore, $\mathrm{NO}_{\mathrm{x}}$ emissions from all materials studied were low and according to the guidelines of EU countries (EC, 2001; ELOT, 2011) for small units $\left(200-350 \mathrm{mg} / \mathrm{Nm}^{3}\right)$. The lower $\mathrm{NO}_{\mathrm{x}}$ levels of almond shells, despite their higher fuel- $\mathrm{N}$ among the biofuels tested, could be a result of a temporary reducing environment created by the large amount of volatiles of this residue (81.5\%), which favored $\mathrm{NO}_{\mathrm{x}}$ decomposition.

Present gaseous emission values were comparable to those reported in literature for similar fuels, while those of $\mathrm{NO}_{\mathrm{x}}$ were significantly lower. For peach pits $\mathrm{CO}$ emissions varied between
600 and 680 ppm $_{\mathrm{v}}$ (Rabacal et al., 2013), for Brazilian nut shells between 50 and $400 \mathrm{ppm}_{\mathrm{V}}$ (Cardozo et al., 2014), for palm kernels between 2,000 and 14,000 $\mathrm{ppm}_{\mathrm{v}}$ (Pawlak-Kruczek et al., 2020), for oil cake pellets between 1,900 and 6,500 $\mathrm{ppm}_{\mathrm{V}}$ (Kraszkiewicz et al., 2015) and for olive pruning pellets were $1,800 \mathrm{ppm}_{\mathrm{V}}$ (Garcia-Maraver et al., 2014). On the other hand, $\mathrm{NO}_{\mathrm{x}}$ emissions were found for peach pits $300-600 \mathrm{mg} / \mathrm{m}^{3}$ (Rabacal et al., 2013), for Brazilian nut shells $180-270 \mathrm{mg} / \mathrm{m}^{3}$ (Cardozo et al., 2014), for palm kernels between 90 and 200 ppm $_{\mathrm{v}}$ (Pawlak-Kruczek et al., 2020), for oil cake pellets $230-870 \mathrm{mg} / \mathrm{m}^{3}$ (Kraszkiewicz et al., 2015) and for olive pruning pellets $680 \mathrm{mg} / \mathrm{m}^{3}$ (Garcia-Maraver et al., 2014).

\section{Combustion and Thermal Efficiency}

The combustion performance of the four residues is represented in Table 3. Combustion efficiencies are considered satisfactory for small systems (77\% according to European Standards EN 3035 ), ranging between 84 and $86 \%$. These values were controlled by the flue gas temperatures, which reflected the sensitive heat losses and the concentration of $\mathrm{CO}$ in flue gases, which represented the principal heat losses due to incomplete combustion. Thus, peach kernels, presenting the lowest SL and IL losses, burned with the highest efficiency. It is interesting to note that, the higher amount of air in the case of olive kernels (excess air ratio $\lambda=$ 1.9), increasing fumes flow, seemed to somehow reduce fireplace temperature and therefore increase $\mathrm{CO}$ level and gaseous heat losses (IL). Moreover, the thermal efficiency of the system, shown in Table 3, was affected by the combustion efficiency of the fuel and it was higher for peach kernels, due to improved combustion in the furnace and improved heat recovery in system tubes, by increasing the temperature difference between the forward and return flow of water to the boiler $\left(\Delta \mathrm{T}_{\mathrm{w}}=26.2^{\circ} \mathrm{C}\right)$. The fluctuations observed in the table are owned to the different amounts of each biofuel burned as a function of time, when the boiler was operated at specific on/off intervals of the feed regulating dimmers. An optimization of fuel rate and excess air ratio toward a lower value could result in higher fireplace temperature (a high flow of air supply cools the furnace), lower $\mathrm{CO}$ emissions due to better combustion, lower oxygen and higher $\mathrm{CO}_{2}$ concentrations in fumes and therefore reduced heat or fuel losses and increased combustion efficiency. This, in turn, would improve heat recovery in tubes and rise thermal efficiency. Furthermore, some modifications in the furnace to increase the residence time of flue gases would lower their temperature at the exhaust and thus sensitive heat losses. 


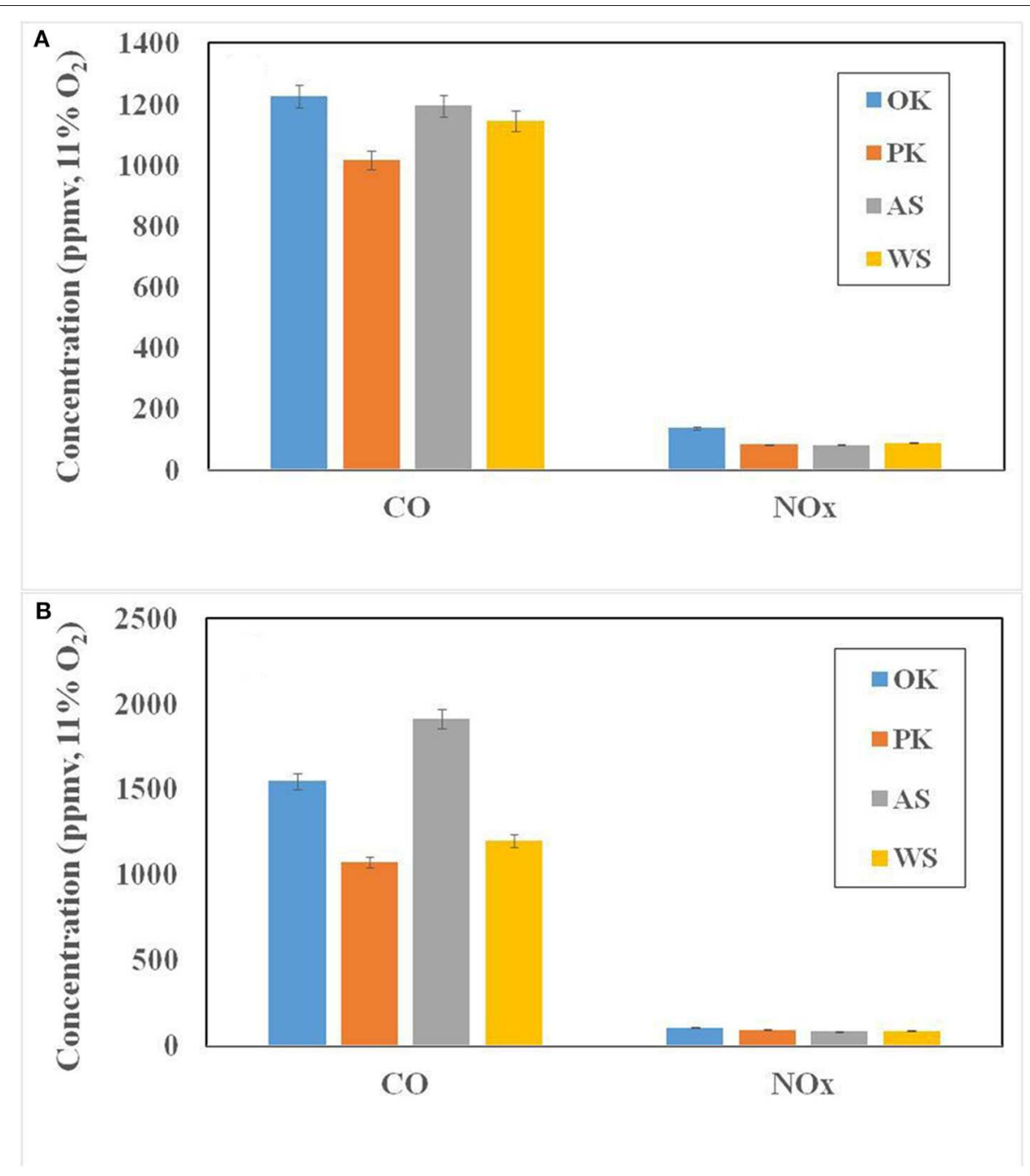

FIGURE 4 | Average pollutant concentrations of gases from raw fuels (A) at steady state and (B) during whole operation of unit.

Nevertheless, boiler efficiency was in accordance with literature data. Values of $91 \%, 83-86 \%$ and $75-83 \%$ have been reported for wood pellets (Kraiem et al., 2016), pine wood and peach pits (Rabacal et al., 2013), respectively. Moreover, for a multi-fuel boiler burning woody materials thermal efficiency was found (Fournel et al., 2015) to be dependent on the ash content of each feedstock, i.e., for ash content $1 \%$ the efficiency was $74 \%$, while for ash content $7 \%$ it dropped to $63 \%$. In another unit, burning forest residues and energy crops, the efficiency varied between 69 and 75\% (Forbes et al., 2014).

\section{Combustion Performance of Agricultural Residues Blends}

Boiler Water Temperature

Figures $\mathbf{5 A}-\mathbf{C}$ represent the evolution of water temperature at the outlet of the boiler as a function of time, during full operation of the furnace, for the mixtures of olive kernels residue with peach kernels, almond and walnut shells. From these figures it can be observed that both the start up phase and the phase when the system was in full operation were delayed when feeding with mixtures of fuels, shifting the curves to higher time values by about $4-6 \mathrm{~min}$. It seems that feeding of blends and consequently burn out were not so homogeneous as theoretically expected.

\section{Flue Gas Temperature and Emissions}

Table 4 shows that flue gas temperatures, which affect sensitive heat losses of the fumes, for all blends at steady state, varied between the values of component fuels. This reveals that the combustion performance of the mixtures was dependent on the contribution of each residue in the blend.

The average $\mathrm{CO}$ and $\mathrm{NO}_{\mathrm{x}}$ emissions ( \pm standard error) at steady state, from all mixtures, are compared with those of raw fuels in Figures 6A-C. $\mathrm{SO}_{2}$ emissions are not presented in the graphs, as they were extremely low $\left(4-20 \mathrm{ppm}_{\mathrm{V}}\right)$. CO values, ranging between 1,121 and 1,212 $\mathrm{ppm}_{\mathrm{V}}$, were kept between 
the values corresponding to component fuels and were within accepted limits for small units (ELOT, 2011). Moreover, $\mathrm{NO}_{\mathrm{x}}$ levels $\left(87-129 \mathrm{ppm}_{\mathrm{v}}\right.$, or $\left.174-258 \mathrm{mg} / \mathrm{m}^{3}\right)$ followed the same trend and were kept below the threshold limits of EU countries (EC, 2001; ELOT, 2011). The best performance in terms of emissions was achieved by OK/PK 50:50 blend.
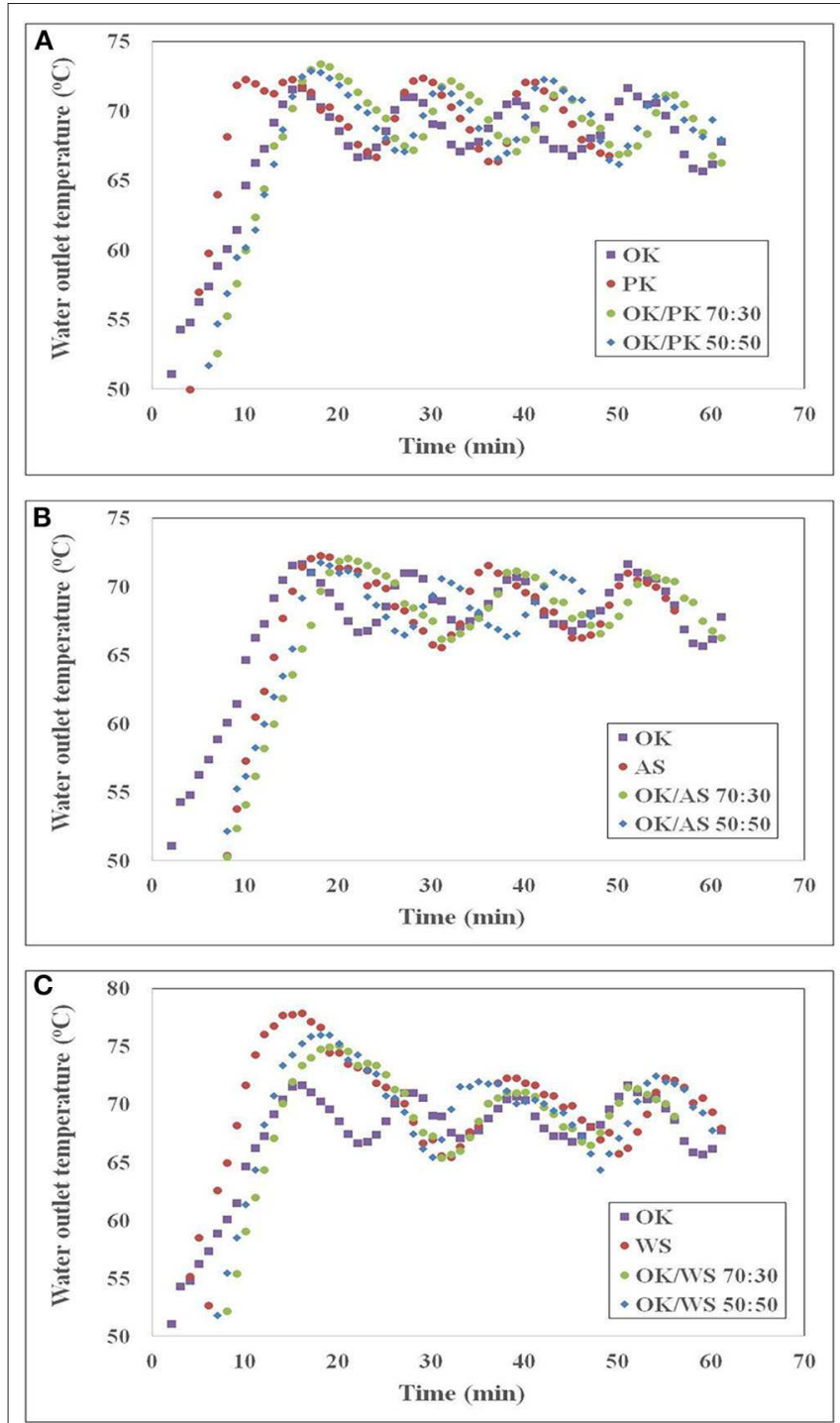

FIGURE 5 | Evolution of boiler water outlet temperature during full operation of the unit for (A) OK/PK, (B) OK/AS, and (C) OKWS mixtures.

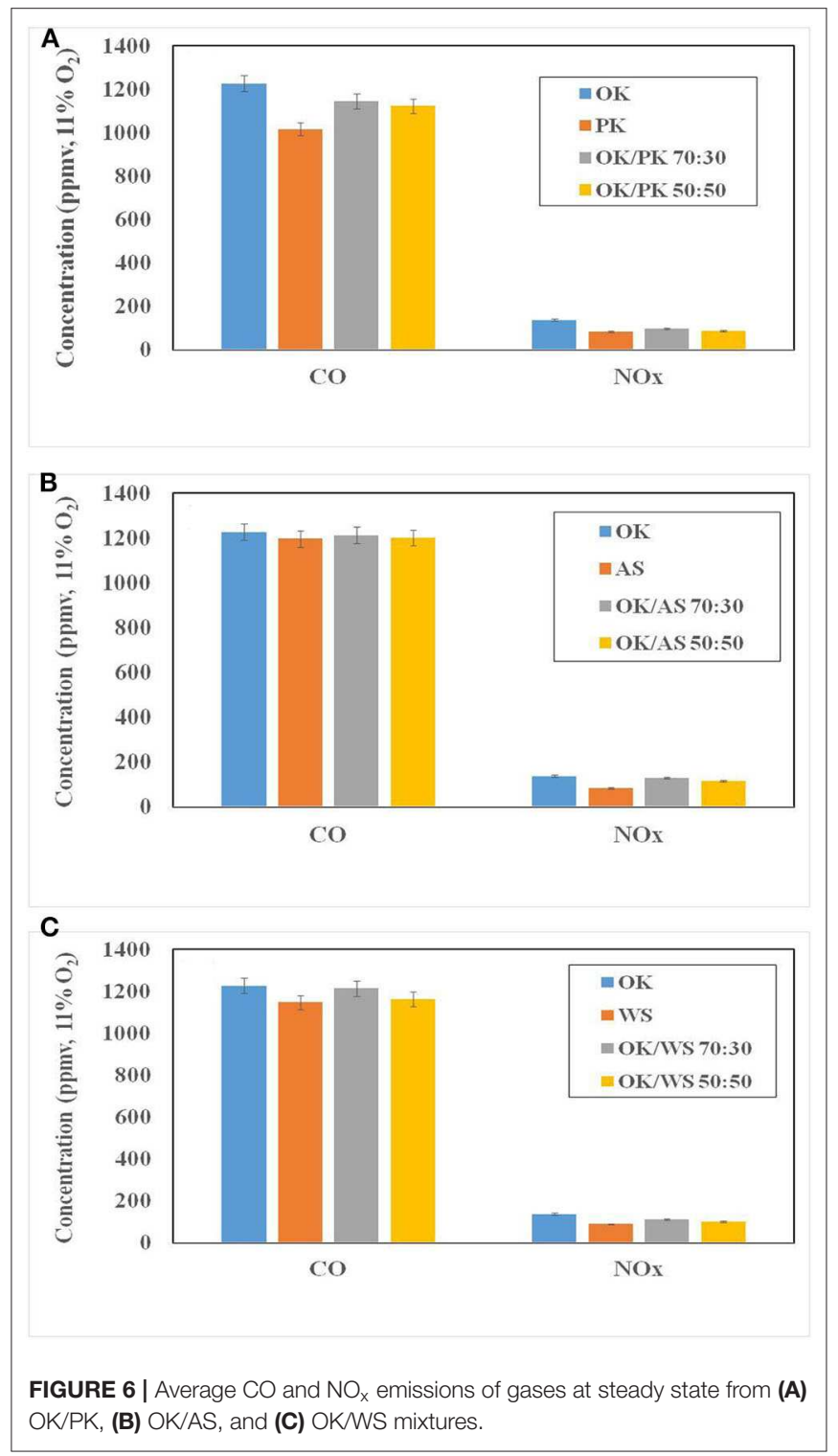

TABLE 4 | Combustion characteristics of fuel mixtures (average values) at steady state.

\begin{tabular}{|c|c|c|c|c|c|c|c|c|c|c|c|c|}
\hline Sample & $\begin{array}{c}\text { Fuel } \\
\text { rate } \\
(\mathrm{kg} / \mathrm{h})\end{array}$ & $\begin{array}{l}\text { Stoich. air } \\
\text { rate per kg } \\
\text { fuel }\left(\mathrm{m}^{3} / \mathrm{h}\right)\end{array}$ & $\begin{array}{c}\text { Excess } \\
\text { air ratio } \\
\lambda\end{array}$ & $\begin{array}{c}\mathrm{CO} \\
\left(\mathrm{pppm}_{\mathrm{V}}\right)\end{array}$ & $\begin{array}{c}\mathrm{SO}_{2} \\
\left(\operatorname{ppm}_{\mathrm{V}}\right)\end{array}$ & $\begin{array}{c}\mathrm{NO}_{\mathrm{x}} \\
\left(\mathrm{ppm}_{\mathrm{v}}\right)\end{array}$ & $\begin{array}{c}T_{f} \\
\left({ }^{\circ} \mathrm{C}\right)\end{array}$ & $\begin{array}{l}\text { SL } \\
(\%)\end{array}$ & $\begin{array}{l}\text { IL } \\
(\%)\end{array}$ & $\begin{array}{c}\mathrm{L}_{\mathrm{a}} \\
(\%)\end{array}$ & $\begin{array}{c}\eta_{c} \\
(\%)\end{array}$ & $\begin{array}{c}\eta_{\mathrm{t}} \\
(\%)\end{array}$ \\
\hline OK/PK 50:50 & 15.7 & 5.1 & 1.66 & 1121.3 & 8.0 & 86.6 & 238.7 & 13.4 & 0.9 & 0.1 & 85.6 & 91.4 \\
\hline OK/AS 70:30 & 14.0 & 5.3 & 1.85 & 1210.8 & 12.5 & 129.0 & 255.1 & 14.3 & 1.0 & 0.2 & 84.5 & 87.7 \\
\hline OK/AS 50:50 & 14.4 & 5.0 & 2.0 & 1199.3 & 19.6 & 113.1 & 253.8 & 14.6 & 0.9 & 0.3 & 84.2 & 87.2 \\
\hline OKWS 50:50 & 13.7 & 5.3 & 1.80 & 1161.2 & 9.9 & 99.1 & 242.6 & 14.1 & 1.0 & 0.1 & 84.8 & 81.6 \\
\hline
\end{tabular}




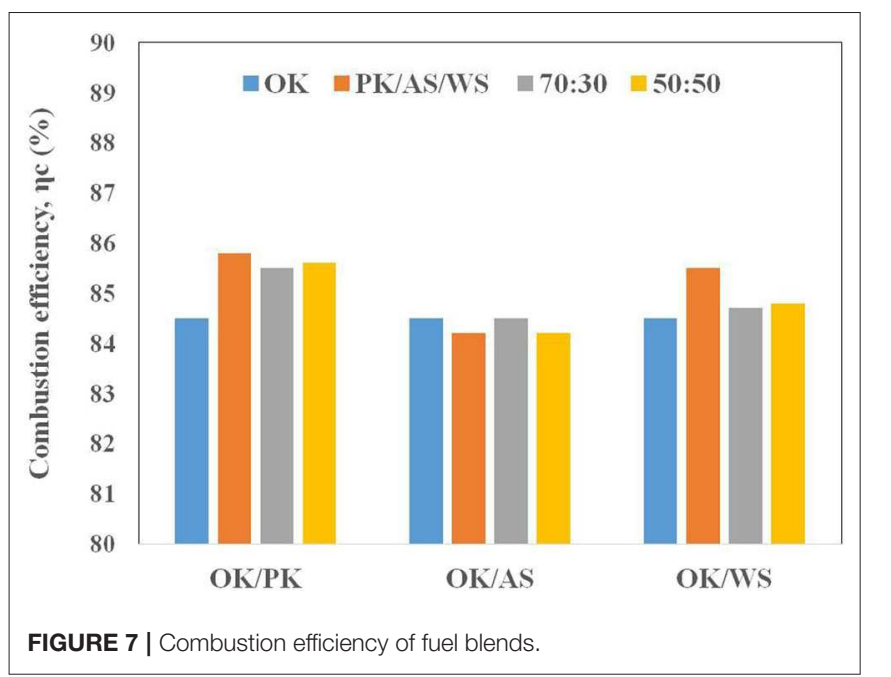

\section{Combustion and Thermal Efficiency}

Combustion efficiencies of olive kernels blends with peach kernels, almond and walnut shells ranged between 84.2 and $85.6 \%$, as indicated in Figure 7. These values were between those corresponding to component materials, but not in proportion to the percentage of each residue in the mixture. As shown in Table 4, combustion efficiency was a result of feedstock type and mass flow, as well as excess air ratio, which defined fireplace and fumes temperatures and consequently heat losses. The highest efficiency was achieved in the case of OK/PK 50:50 blend, which in turn was reflected in the thermal efficiency of the boiler, by improved heat recovery from the flow of water.

\section{CONCLUSIONS}

The agricultural residues studied were characterized by high volatile and low ash contents. Their calorific value was significant ranging between 17.5 and $20.4 \mathrm{MJ} / \mathrm{kg}$. $\mathrm{CO}$ and $\mathrm{NO}_{\mathrm{x}}$ emissions, from all fuels during the whole operation of the unit under the conditions studied, were below legislation limits, while $\mathrm{SO}_{2}$ emissions were negligible. Combustion efficiencies were

\section{REFERENCES}

Ahn, J., and Jang, J. H. (2018). Combustion characteristics of a 16 step grate-firing wood pellet boiler. Renew. Energy 129, 678-685. doi: 10.1016/j.renene.2017.06.015

Caposciutti, G., and Antonelli, M. (2018). Experimental investigation on air displacement and air excess effect on $\mathrm{CO}, \mathrm{CO}_{2}$ and $\mathrm{NO}_{\mathrm{x}}$ emissions of a small fixed bed biomass boiler. Renew. Energy 116, 795-804. doi: 10.1016/j.renene.2017.10.001

Cardozo, E., Erlich, C., Alejo, L., and Fransson, T. H. (2014). Combustion of agricultural residues: an experimental study for small-scale applications. Fuel 115, 778-787. doi: 10.1016/j.fuel.2013.07.054

Carroll, J., and Finnan, J. (2015). The use of additives and fuel blending to reduce emissions from the combustion of agricultural fuels in small scale boilers. Biosyst. Eng. 129, 127-133. doi: 10.1016/j.biosystemseng.201 4.10 .001 satisfactory, ranging between 84 and $86 \%$. Peach kernels, followed by walnut shells burned with the highest efficiency, due to lower sensitive heat losses and losses from incomplete fuel combustion, emitted lower concentrations of toxic gases and increased boiler efficiency by improving the heat recovery in system tubes.

Co-combustion of the agricultural residues could be predicted to a great extent from the combustion of component fuels, which could offer not only environmental, but also economic benefits. By blending olive kernels with peach kernels, almond or walnut shells at percentages up to $50 \%$, the overall efficiency of the system in terms of emissions and degree of combustion was improved. The pest performance was achieved by olive kernels/peach kernels 50:50 blend.

Combustion efficiency was a result of feedstock type, mass flow and excess air ratio. Robust control of combustion air supply is needed and determination of optimal parameters.

\section{DATA AVAILABILITY STATEMENT}

All datasets generated for this study are included in the article/supplementary material.

\section{AUTHOR CONTRIBUTIONS}

DV: supervisor, evaluation of results, and paper writing. DL: experiments. ES: experiments. AV: experiments. SS: evaluation of results. GB: technical support and evaluation of results. All authors: contributed to the article and approved the submitted version.

\section{ACKNOWLEDGMENTS}

The authors kindly thank AVEA Chania Oil Cooperatives, the Union of Agricultural Cooperatives of Giannitsa and private companies Agrinio and Hohlios for providing the fuels, as well as the laboratories of Hydrocarbons Chemistry and Technology and Inorganic and Organic Geochemistry, of the Technical University of Crete, for the CHNS and XRF analyses.

Carvalho, L., Wopienka, E., Pointner, C., Lundgren, J., Kumar, V., Haslinger, W., et al. (2013). Performance of a pellet boiler with agricultural fuels. Appl. Energy 104, 286-296. doi: 10.1016/j.apenergy.2012.10.058

EC (2001). Directive 2001/80/EC of the European Parliament and of the Council of 23 October 2001, on the Limitation of Emissions of Certain Pollutants into the Air from Large Combustion Plants.

ELOT (2011). EN 303.05/1999. Limit Values for $\mathrm{CO}$ and $\mathrm{NO}_{x}$ Emissions for New Thermal Units Using Solid Biofuels. FEK 2654/B/9-11-2011.

EU (2014). Leaders Agree 2030 Climate and Energy Goals. Available online at: http://ec.europa.eu/clima/news/articles/news_2014102401_en.htm

Forbes, E., Easson, D., Lyons, G., and McRoberts, W. (2014). Physico-chemical characteristics of eight different biomass fuels and comparison of combustion and emission results in a small scale multi-fuel boiler. Energy Conv. Managem. 87, 1162-1169. doi: 10.1016/j.enconman.2014.06.063

Fournel, S., Palacios, J. H., Morissette, R., Villeneuve, J., Godbout, S., Heitza, M., et al. (2015). Influence of biomass properties on technical and environmental 
performance of a multi-fuel boiler during on-farm combustion of energy crops. Appl. Energy 141, 247-259. doi: 10.1016/j.apenergy.2014.12.022

Garcia-Maraver, A., Zamorano, M., Fernandes, U., Rabacal, M., and Costa, M. (2014). Relationship between fuel quality and gaseous and particulate matter emissions in a domestic pellet-fired boiler. Fuel 119, 141-152. doi: 10.1016/j.fuel.2013.11.037

Kortelainen, M., Jokiniemi, J., Nuutinen, I., Torvela, T., Lamberg, H., Karhunen, T., et al. (2015). Ash behaviour and emission formation in a small-scale reciprocating-grate combustion reactor operated with wood chips, reed canary grass and barley straw. Fuel 143, 80-88. doi: 10.1016/j.fuel.2014.11.006

Kraiem, N., Lajili, M., Limousy, L., Said, R., and Jeguirim, M. (2016). Energy recovery from Tunisian agri-food wastes: Evaluation of combustion performance and emissions characteristics of green pellets prepared from tomato residues and grape marc. Energy 107, 409-418. doi: 10.1016/j.energy.2016.04.037

Kraszkiewicz, A., Przywara, A., Kachel-Jakubowska, M., and Lorencowicz, E. (2015). Combustion of plant biomass pellets on the grate of a low power boiler. Agricul. Agricul. Sci. Proc. 7, 131-138. doi: 10.1016/j.aaspro.2015.12.007

McKendry, P. (2002). Energy production from biomass (part 1): overview of biomass. Bioresour. Technol. 83, 37-46. doi: 10.1016/S0960-8524(01)00118-3

Moyers, C. G., and Baldwin, G. W. (1997). "Psychrometry, evaporative cooling and solids drying," in Perry's Chemical Engineers' Handbook, 7th Edn, eds R. H. Perry and D. W. Green (New York, NY: Mc Graw Hill).

Nizetic, S., Papadopoulos, A., Radica, G., Zanki, V., and Arici, M. (2019). Using pellet fuels for residential heating: a field study on its efficiency and the users' satisfaction. Energy Build. 184, 193-204. doi: 10.1016/j.enbuild.2018.12.007

Pawlak-Kruczek, H., Arora, A., Moscicki, K., Krochmalny, K., Sharma, S., and Niedzwiecki, L. (2020). A transition of a domestic boiler from coal to biomassEmissions from combustion of raw and torrefied Palm Kernel shells (PKS). Fuel 263, 116-124. doi: 10.1016/j.fuel.2019.116718

Pizzi, A., Foppa Pedretti, E., Duca, D., Rossini, G., Mengarelli, C., Ilari, A., et al. (2018). Emissions of heating appliances fuelled with agropellet produced from vine pruning residues and environmental aspects. Renew. Energy 121, 513-520. doi: 10.1016/j.renene.2018.01.064

Rabacal, M., Fernandes, U., and Costa, M. (2013). Combustion and emission characteristics of a domestic boiler fired with pellets of pine, industrial wood wastes and peach stones. Renew. Energy 51, 220-226. doi: $10.1016 /$ j.renene.2012.09.020
Sippula, O., Lamberg, H., Leskinen, J., Tissari, J., and Jokiniemi, J. (2017). Emissions and ash behaviour in a $500 \mathrm{~kW}$ pellet boiler operated with various blends of woody biomass and peat. Fuel 202, 144-153. doi: 10.1016/j.fuel.2017.04.009

Sutar, K. B., Kohli, S., Ravi, M. R., and Ray, A. (2015). Biomass cookstoves: a review of technical aspects. Renew. Sustainable Energy Rev. 41, 1128-1166. doi: 10.1016/j.rser.2014.09.003

Uslo, A., Gomez, N. C., and Belda, M. S. (2010). Demand for Lignocellulosic Biomass in Europe. Elobio Biofuels Policies for Dynamic Markets. Available online at: https://www.elobio.eu/fileadmin/elobio/user/docs/Additional_D_to_WP3Linocellulosic_biomass.pdf

Vamvuka, D. (2009). Biomass, Bioenergy and the Environment. Salonica: Tziolas Publications.

Vamvuka, D., Trikouvertis, M., Pentari, D., Alevizos, G., and Stratakis, A. (2017). Characterization and evaluation of fly and bottom ashes from combustion of residues from vineyards and processing industry. J. Energy Instit. 90, 574-587. doi: 10.1016/j.joei.2016.05.004

Vamvuka, D., and Tsoutsos, T. (2002). Energy exploitation of agricultural residues in Crete. Energy Expl. Exploit. 20, 113-121. doi: 10.1260/014459802760170439

Zeng, T., Pollex, A., Weller, N., Lenz, V., and Nelles, M. (2018). Blended biomass pellets as fuel for small scale combustion appliances: effect of blending on slag formation in the bottom ash and pre-evaluation options. Fuel 212, 108-116. doi: 10.1016/j.fuel.2017.10.036

Conflict of Interest: GB was employed by the company Energy Mechanical of Crete S.A.

The remaining authors declare that the research was conducted in the absence of any commercial or financial relationships that could be construed as a potential conflict of interest.

Copyright $\odot 2020$ Vamvuka, Loukeris, Stamou, Vlasiadis, Sfakiotakis and Bandelis. This is an open-access article distributed under the terms of the Creative Commons Attribution License (CC BY). The use, distribution or reproduction in other forums is permitted, provided the original author(s) and the copyright owner(s) are credited and that the original publication in this journal is cited, in accordance with accepted academic practice. No use, distribution or reproduction is permitted which does not comply with these terms. 